\title{
Controle interno da qualidade em citopatologia ginecológica: um estudo de 48.355 casos
}

\author{
The internal quality control system in gynecological cytopathology: an study of 48,355 cases
}

\author{
Roberto Alfonso Arcuri \\ Katia Cilene Ferreira da Cunha ${ }^{2}$ \\ Elizabeth de Carvalho Alves ${ }^{3}$ \\ Antonio Alexandre de Castro ${ }^{4}$ \\ Regina Ávila Maciel ${ }^{3}$ \\ Ana Cristina Rosmanino 4 \\ Priscila Louise da Silva ${ }^{4}$ \\ Gisela Camelier Xavier ${ }^{4}$
}

\begin{tabular}{|c|c|}
\hline unitermos & resumo \\
\hline $\begin{array}{l}\text { Controle interno } \\
\text { Qualidade } \\
\text { Citopatologia ginecológica }\end{array}$ & $\begin{array}{l}\text { Todos os sistemas de avaliação de desempenho em laboratórios de citopatologia exigem um } \\
\text { programa de controle interno da qualidade estabelecido e executado. O presente estudo tem por } \\
\text { objetivo identificar os resultados do programa e o desempenho dos citotécnicos. Para tanto } \\
\text { foram revistos os laudos, emitidos pelos citotécnicos e pelos citopatologistas, de } 48.355 \text { exames } \\
\text { citopatológicos ginecológicos realizados durante } 21 \text { meses. Foram identificados } 2.299 \text { casos } \\
\text { anômalos encaminhados ao citopatologista, e confirmados } 1.132 ; 2.973 \text { casos de alto risco foram } \\
\text { detectados e } 998 \text { anômalos identificados. A revisão de } 10 \% \text { dos negativos representou } 3.180 \\
\text { casos, com identificação de } 77 \text { anômalos. Os anômalos totais detectados foram: } 1.176 \text { ASCUS, } 60 \\
\text { AGUS, } 819 \text { NIC I/HPV, } 85 \text { NIC II, } 33 \text { NIC III, } 11 \text { carcinomas escamosos, } 17 \text { adenocarcinomas, } \\
\text { cinco VAIN I e um VAIN III. Os ASCUS/AGUS foram } 56 \% \text {, e as outras lesões representaram } 44 \% \text {. } \\
\text { Os } 4,56 \% \text { de anômalos detectados concordam com os valores propostos por Cardin ( } 3 \% \text { a } 5 \% \text { ), } \\
\text { pelo sistema Bethesda ( } 4 \% \text { a } 6 \% \text { ) e por Kurman et al. ( } 5 \% \text { ) ( } 4,6,7) \text {. O citopatologista revisou } \\
17,48 \% \text { dos casos ( } n=8.452 \text { ). Dos } 77 \text { (0,16\% do total) anômalos identificados no reescrutínio, } \\
59 \text { (0,12\%) foram ASCUS, seis (0,01\%) AGUS e } 12 \text { (0,02\%) NIC I. O presente estudo mostra } \\
\text { resultados do controle interno da qualidade desenvolvido em laboratório particular e fornece } \\
\text { dados relevantes para o planejamento de um programa de prevenção do câncer uterocervical. }\end{array}$ \\
\hline
\end{tabular}

$\begin{array}{rr}\text { Roberto Alfonso Arcuri }^{1} & \text { Katia Cilene Ferreira da Cunha }^{2} \\ \text { Elizabeth de Carvalho Alves }^{3} \\ \text { Antonio Alexandre de Castro }^{4} \\ \text { Regina Ávila Maciel }^{3} \\ \text { Ana Cristina Rosmanino }^{4} \\ \text { Priscila Louise da Silva } \\ \text { Cisela Camelier Xavier }^{4}\end{array}$




\section{Introdução}

Existe um consenso mundial de que o câncer invasor de colo uterino pode ser evitado através do diagnóstico precoce e do tratamento das suas lesões precursoras. Para este fim, a citopatologia exfoliativa cervical corada pelo método de Papanicolaou é o instrumento ideal, pela sua alta sensibilidade, simplicidade e baixo custo $(5,6,9)$.

Segundo dados da Secretaria Estadual da Saúde do Paraná e da Sociedade Brasileira de Patologia - baseados em 857.786 exames preventivos realizados no estado do Paraná, no período de 1/10/1997 a 30/9/1999 -, identificaram-se $17.025(1,99 \%)$ lesões precursoras, 414 (0,05\%) cânceres invasivos e 840.347 negativos (Bleggi Torres, L.F. \& Collaço, L.M., comunicação pessoal).

Todos os sistemas de avaliação de desempenho em laboratórios de citopatologia coincidem na necessidade de um programa de controle interno da qualidade perfeitamente estabelecido e executado. Diversos trabalhos reportam falhas nos diagnósticos citopatológicos, com especial ênfase nos falso-negativos $(3,5,10,12,13,15,18,19)$, sem fornecer informações sobre os resultados do programa de controle interno da qualidade.

O objetivo do programa é detectar erros diagnósticos em qualquer estágio do processo, priorizando os falsonegativos, considerando que os falso-positivos serão reconhecidos no decorrer das novas investigações e, portanto, seus efeitos serão minimizados. Os falso-negativos limitam o diagnóstico preciso da doença e postergam o início da terapêutica, com graves conseqüências para a paciente.

Em 1987, Anderson et al. (1) definiram como falsonegativo o caso interpretado com atipias benignas ou insatisfatório no escrutínio e diagnosticado como displasia intensa ou mais durante a revisão. Esfregaços subdiagnosticados são os que exibem uma discrepância menor, porém maior que um grau de diferença com o diagnóstico final (por exemplo, interpretado com atipias benignas no escrutínio e diagnosticado como displasia leve ou moderada durante a revisão). Em 19.088 casos revistos, encontraram-se 407 (2,13\%) subdiagnosticados e 193 (1,01\%) falso-negativos. Deste conjunto, um terço foi identificado na revisão hierárquica e dois terços revendo-se os esfregaços negativos por ocasião de um caso subseqüente anormal. Cardin (4) relatou um valor mensal inferior a $5 \%$ de falso-negativos. Num exemplo sobre dados da qualidade em citopatologia, Travers (16) observou que, em 6.538 casos, diagnosticaram-se 291 (4,45\%) inadequados, $80(1,22 \%)$ falso-negativos e $17(0,26 \%)$ falsopositivos.

Os falso-negativos podem ocorrer em duas circunstâncias: 1 ) a paciente tem de fato uma anormalidade, mas as células representativas desta anormalidade não se encontram presentes nas preparações citopatológicas; 2) a paciente tem de fato uma anormalidade, e células representativas desta anormalidade se encontram presentes nas preparações citopatológicas, mas não foram detectadas ou foram mal interpretadas como não-representativas de uma anormalidade presente $(5,16)$.

Os estudos para identificar a origem dos falso-negativos não representam um trabalho infecundo nem um exercício especulativo. Existem importantes implicações tanto na maneira com que os falso-negativos são detectados como nos efeitos que estes exames terão na qualidade geral da prática da citopatologia, sendo necessários maiores esforços para minimizar sua incidência.

Um reescrutínio repetido de $10 \%$ dos esfregaços negativos é um método tradicional para medir a qualidade em citopatologia. Este procedimento detecta somente uma parte dos casos falso-negativos devidos a má interpretação do material presente na lâmina e é incapaz de detectar os falso-negativos decorrentes da ausência de material diagnóstico nas lâminas estudadas.

Por estas razões, outros métodos devem ser utilizados para aferir a qualidade, tais como a revisão dos negativos prévios quando acontece um caso novo anômalo e a correlação dos esfregaços negativos prévios com estudos histopatológicos que exibam alterações importantes, $(5,6,14,16)$.

\section{Objetivo}

Identificar o desempenho dos citotécnicos no escrutínio e reescrutínio e o número de casos revistos pelo citopatologista, visando a conhecer os resultados do controle interno da qualidade em citopatologia ginecológica.

\section{Material e método}

\section{Material}

Avaliaram-se os dados de 48.355 exames realizados durante 21 meses (12 meses de 1999 e nove meses de 2000). 
Realizaram-se os exames no laboratório O Aleph, empresa particular cuja clientela originou-se de consultórios médicos particulares.

\section{Nomenclatura utilizada}

Utilizou-se a nomenclatura proposta pelo sistema Bethesda (6), pelo Instituto Nacional de Câncer/Sociedade Brasileira de Citopatologia (11) e pela Comissão Técnica de Análises Clínicas e de Patologia do Inmetro (8):

- caso ginecológico negativo é aquele que apresenta padrão citopatológico normal ou com alterações reacionais benignas;

- caso ginecológico anormal ou anômalo é aquele que apresenta padrão citopatológico com atipias celulares de significado indeterminado (ASCUS ou AGUS), lesão intra-epitelial de baixo grau (efeito citopático do HPV, displasia leve, NIC I, VAIN I), lesão intraepitelial de alto grau (displasia moderada, displasia intensa, carcinoma in situ, NIC II, NIC III, VAIN II, VAIN III) ou lesão invasora;
- paciente de alto risco é aquela que apresenta exames clínico, colposcópico, citopatológico ou anatomopatológico anormais prévios ou, ainda, informação clínica relevante (sangramentos anômalos, colo com lesões suspeitas, parceiros de risco, etc.);

- reescrutínio é a revisão rotineira de $10 \%$ dos casos negativos pelo revisor do escrutínio;

- revisão é o reestudo das lâminas citopatológicas anômalas pelo médico citopatologista após o estudo realizado pelo escrutinador ou pelo revisor de escrutínio;

- reexame é a revisão dos casos dos pacientes considerados de alto risco.

\section{Fluxograma}

O fluxograma do programa de controle interno da qualidade em citopatologia ginecológica (Figura) determina:

1) o médico avalia as requisições de todos os exames para distinguir os casos de alto risco clínico e os encaminha ao citotécnico sênior;

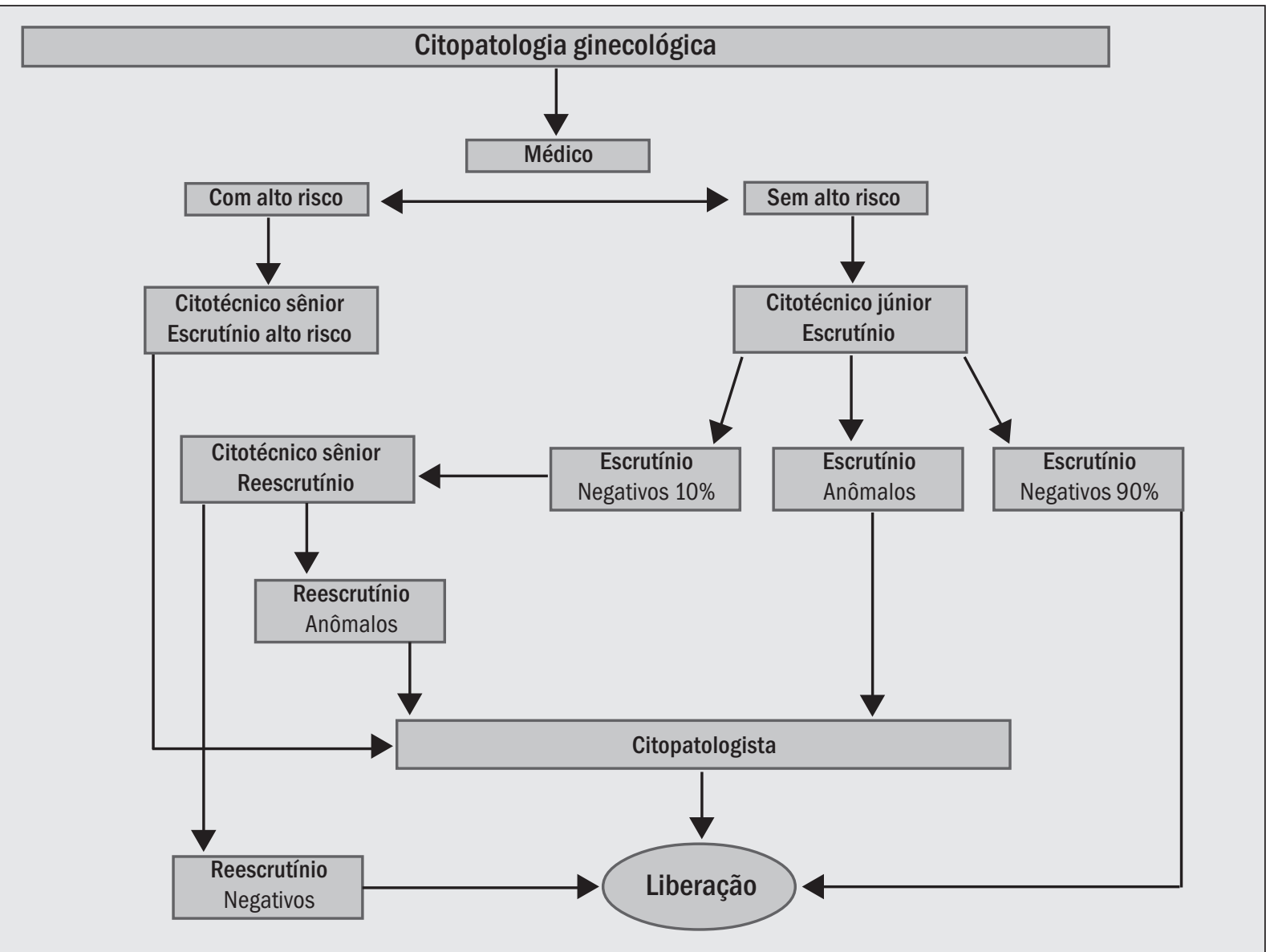

Figura - Fluxograma do programa de controle interno da qualidade em citopatologia ginecológica 
2) o citotécnico sênior faz o escrutínio dos exames de alto risco e os encaminha ao citopatologista para reexame;

3) os casos sem alto risco clínico são encaminhados ao citotécnico júnior, que, inicialmente, verifica a existência de anômalos prévios; nesta circunstância, o exame passa como alto risco ao citotécnico sênior;

4) nos restantes - sem alto risco clínico nem exame prévio anômalo -, o citotécnico júnior faz o escrutínio;

5) os anômalos, insatisfatórios e satisfatórios limitados por hemorragia detectados pelo citotécnico júnior são encaminhados ao citopatologista para revisão;

6) os negativos, com ou sem alterações inflamatórias, são liberados;

7) o sistema informatizado bloqueia automaticamente $10 \%$ dos exames negativos, e o citotécnico sênior faz o reescrutínio. Havendo confirmação do diagnóstico, o exame é liberado;

8) caso se considere anômalo o resultado no reescrutínio, o exame é encaminhado ao citopatologista para revisão.

\section{Método}

Todos os exames considerados anômalos pelos citotécnicos (incluindo os insatisfatórios e os limitados por hemorragia), todos os de alto risco e os casos liberados como negativos e bloqueados pelo computador como parte dos 10\% encaminhados para revisão são registrados em ficha individual contendo os dados do caso, as opiniões do citotécnico, do citopatologista e as interconsultas, assim como informações sobre exames prévios e as datas dos respectivos registros.

Foram revistos os dados relativos ao ano de 1999 (total de 24.709 casos) e os referentes aos meses de janeiro, março, abril, maio, junho, agosto, setembro, outubro e novembro de 2000 (23.646 casos). Os dados dos meses de fevereiro e julho de 2000 foram desconsiderados por falhas na totalização de alguns itens.

Realizou-se a tabulação dos dados segundo revisões, exames com alto risco e reescrutínio dos $10 \%$ dos exames negativos, observando-se os casos submetidos e os confirmados por cada tipo de patologia, em valores absolutos e relativos.

\section{Resultados}

Do total de 48.355 casos de citopatologia ginecológica diagnosticados, os dados do programa mostram:

\section{Revisões}

Encaminhados ao citopatologista 2.299 casos (4,75\% do total) considerados anômalos e confirmados 1.132 $(49,24 \%$ dos casos encaminhados e $2,34 \%$ do total) (Tabela 1).

\section{Exames com alto risco}

Identificados 2.973 casos (6,15\% do total) com história de alto risco para alterações cervicais e observados 998 anômalos (33,57\% do total dos exames de alto risco estudados e $2,06 \%$ do total) (Tabela 1 ).

\section{Reescrutínio dos $10 \%$ dos exames negativos}

De um total teórico de 4.308 exames que deveriam passar pelo reescrutínio, recuperaram-se os dados de 3.180 casos ou $7,38 \%$ dos casos negativos liberados. Neste conjunto identificaram-se - na revisão - 77 casos com alterações $(2,42 \%$ de anômalos sobre o total de $10 \%$ e $0,16 \%$ sobre o total de citopatologias ginecológicas estudadas) (Tabela 1).

\section{Resultados do controle interno da qualidade em citopatologia ginecológica em}

Tabela 148.355 exames realizados em 21 meses (1999-2000)

\begin{tabular}{lccccc}
\hline & $\begin{array}{c}N^{0} \text { de revisões } \\
\text { ou reexames }\end{array}$ & $\begin{array}{c}\% \text { do total de } \\
\text { exames (48.355) }\end{array}$ & $\begin{array}{c}\mathbf{N}^{0} \text { de anomalos } \\
\text { confirmados }\end{array}$ & $\begin{array}{c}\% \text { do total de } \\
\text { revisöes ou reexames }\end{array}$ & $\begin{array}{c}\% \text { do total de } \\
\text { exames (48.355) }\end{array}$ \\
Revisões & 2.299 & 4,75 & 1.132 & 49,24 & 2,34 \\
Alto risco & 2.973 & 6,15 & 998 & 33,57 & 2,06 \\
$10 \%$ & 3.180 & 6,58 & 77 & 2,42 & 0,16 \\
\hline Total & $\mathbf{8 . 4 5 2}$ & $\mathbf{1 7 , 4 8}$ & $\mathbf{2 . 2 0 7}$ & $\mathbf{2 6 , 1 1}$ & $\mathbf{4 , 5 6}$ \\
\hline
\end{tabular}


Distribuição dos 2.207 casos anômalos diagnosticados entre 8.452 casos revistos pelo médico citopatologista, segundo pertencentes às revisöes dos anômalos, ao reexame dos casos de

Tabela 2 alto risco, ao reescrutínio dos 10\% dos negativos e ao total

\begin{tabular}{lcccccc} 
Diagnóstico & $\begin{array}{c}\text { Revisão } \\
\text { dos casos } \\
\text { anômalos }\end{array}$ & $\begin{array}{c}\text { Reexame } \\
\text { dos casos } \\
\text { de alto risco }\end{array}$ & $\begin{array}{c}\text { Reescrutínio } \\
\text { dos } 10 \% \text { dos } \\
\text { casos negativos }\end{array}$ & $\begin{array}{c}\text { Total } \\
\text { \% do total de } \\
\text { casos revistos pelo } \\
\text { médico citopatologista }\end{array}$ & $\begin{array}{c}\text { \% do total } \\
\text { geral de casos } \\
(48.355)\end{array}$ \\
$\begin{array}{l}\text { Negativos } \\
\text { ASCUS }\end{array}$ & 1.167 & 1.975 & 3.103 & 6.245 & 73,89 & 12,91 \\
AGUS & 592 & 525 & 59 & 1.176 & 13,91 & 2,43 \\
NIC I & 35 & 19 & 6 & 60 & 0,71 & 0,12 \\
NIC II & 428 & 379 & 12 & 819 & 9,69 & 1,69 \\
NIC III & 42 & 43 & 0 & 85 & 1,01 & 0,18 \\
Carcinoma & 18 & 15 & 0 & 33 & 0,39 & 0,07 \\
escamocelular & 6 & 5 & 0 & 11 & 0,13 & 0,02 \\
Adenocarcinoma & 9 & 8 & 0 & 17 & 0,2 & 0,04 \\
VAIN I & 2 & 3 & 0 & 5 & 0,06 & 0,01 \\
VAIN III & 0 & 1 & 0 & 1 & 0,01 & 0 \\
Totais anômalos & 1.132 & 998 & 77 & 2.207 & 26,11 & $\mathbf{1 7}$ \\
\hline Total & 2.299 & 2.973 & 3.180 & $\mathbf{8 . 4 5 2}$ & 100 & 17,48
\end{tabular}

\section{Análise dos anômalos diagnosticados}

No total de 48.355 casos identificaram-se: 1.176 ASCUS, 60 AGUS, 943 lesões intra-epiteliais (819 NIC I/ HPV, 85 NIC II, 33 NIC III, cinco VAIN I e um VAIN III) e 28 lesões invasivas (11 carcinomas escamosos e 17 adenocarcinomas) (Tabela 2).

Os casos de ASCUS/AGUS representaram 56\% (1.236 casos), e o resto dos anômalos, $44 \%$ (971 casos) (Tabela 3).

No total, registraram-se dez casos limitados por hemorragia e dois com avaliação prejudicada por hemorragia, todos confirmados pelo citopatologista.

Dos $77(0,16 \%$ do total) anômalos identificados no reescrutínio, $59(0,12 \%)$ corresponderam a ASCUS, seis $(0,01 \%)$ a AGUS e $12(0,02 \%)$ a NIC I.

\section{Discussão}

O controle interno da qualidade em citopatologia ginecológica visa a identificar casos falso-negativos (amostras com células anormais presentes, porém não-detectadas ou mal interpretadas) e determinar qual o percentual a ser revisto ou reexaminado para atingir um patamar confiável de bons resultados. Pode ser considerado ideal o reexame de todos os casos, porém, sendo isto impossível, deve-se encontrar o equilíbrio entre o ideal e o possível.

Nas discussões sobre o Programa Nacional de Prevenção de Câncer de Colo Uterino, organizado pelo Instituto Nacional de Câncer (RJ/MS) e com a participação das Sociedades Científicas e Secretarias Estaduais de Saúde*, ficou estabelecido, inicialmente, que deviam ser revistos todos os casos insatisfatórios e satisfatórios, porém limitados por hemorragia, casos de alto risco, anômalos e negativos aleatórios até completar $10 \%$ do total dos exames realizados. Posteriormente, foi definido que o reescrutínio seria de, pelo menos, $5 \%$ dos negativos.

Alguns autores (20), realizando uma revisão entre pares de $1,3 \%$ de todos os casos de citopatologia ginecológica durante um determinado período, adicionaram um comentário sobre alguns aspectos do laudo original em $24,9 \%$ dos casos, sendo menos da metade (43\%) referida à fase pós-analítica (descrição da microscopia e do diagnós-

\footnotetext{
*Reunião de Proposta do Sistema de Monitorização do Controle de Qualidade Interno em Citopatologia. Coordenação Nacional de Controle do Tabagismo, Prevenção e Vigilância do Câncer (Conprev), Instituto Nacional de Câncer (Inca), Ministério da Saúde, Governo Federal. Rio de Janeiro, 1999-2000.
} 


\begin{tabular}{lccccc} 
Tabela 3 & \multicolumn{4}{l}{$\begin{array}{l}\text { Distribuição dos } \\
\text { dos outros anômalos }\end{array}$} \\
& $\begin{array}{l}N^{0} \text { total } \\
\text { de anômalos }\end{array}$ & $\begin{array}{c}\mathbb{N}^{0} \\
\text { ASCUS/AGUS }\end{array}$ & $\begin{array}{c}\text { \% ASCUS/AGUS } \\
\text { do total de anômalos }\end{array}$ & $\begin{array}{c}\mathbb{N}^{0} \text { de outros } \\
\text { anômalos }\end{array}$ & $\begin{array}{c}\text { \% de outros anômalos } \\
\text { do total de anômalos }\end{array}$ \\
Revisões & 1.132 & 627 & 55,39 & 505 & 44,61 \\
Alto risco & 998 & 544 & 54,51 & 454 & 45,49 \\
$10 \%$ & 77 & 65 & 84,42 & 12 & 15,58 \\
\hline Total & $\mathbf{2 . 2 0 7}$ & 1.236 & 56 & 971 & 44 \\
\hline
\end{tabular}

tico, recomendações e codificação). Em 1,1\% dos casos houve sugestões referentes ao diagnóstico, e em 0,4\%, em relação às recomendações.

Anderson et al. (1) referem em $4 \%$ a taxa de casos ginecológicos que são lidos pelos citopatologistas.

Baker et al. (2) concluíram que os falso-negativos possuem um número quantitativamente menor de células que os verdadeiros positivos. Dados semelhantes obteve o Trent Gynaecological Pathology Quality Assurance Group (17), estabelecendo que as duas maiores causas de amostras inadequadas são a escassa celularidade e a ocultação celular.

O sistema Bethesda (6) afirma que o número total de anômalos diagnosticados deve corresponder a $4 \%$ a $6 \%$ do total de casos examinados, ou três vezes o número de lesões intra-epiteliais (LSIL e HSIL). Já Kurman et al. (7) indicam uma taxa de $5 \%$ de anormalidades citopatológicas de baixo grau, enquanto Cardin (4) observa valores entre $3 \%$ e $5 \%$ de casos anômalos. Nossos valores de 4,56\% de anômalos se encontram dentro do padrão internacional. Poderiam ser considerados valores altos quando comparados com os dados do programa do Paraná (2,04\% de anômalos totais) (Bleggi Torres, L.F. \& Collaço, L.M., comunicação pessoal), mas podem também espelhar uma população específica de pacientes com concentração destas patologias e, como conseqüência, com repetição de exames para controle.

Segundo Bleggi Torres (comunicação pessoal), o número de falso-negativos aceitáveis detectados no reescrutínio dos $10 \%$ de casos negativos liberados pelos citotécnicos varia de $4 \%$ a $8 \%$. Os 77 casos $(0,16 \%$ do total) anômalos identificados no reescrutínio dos $10 \%$ dos casos negativos de nosso material não representaram falsonegativos segundo critérios de Anderson et al. (1). Entre eles houve 12 casos $(0,02 \%)$ subdiagnosticados.
Na experiência do Programa Estadual de Prevenção e Controle do Câncer Ginecológico do Paraná, o número de casos diagnosticados como ASCUS foi de $4 \%$, e o de AGUS foi de $0,46 \%$. Houve $12,8 \%$ dos casos originalmente diagnosticados como ASCUS que, na revisão, foram considerados lesões de alto grau (Bleggi Torres, L.F. \& Collaço L.M., comunicação pessoal). Nosso percentual de ASCUS/ AGUS foi inferior, correspondendo o primeiro a $2,43 \%$ e o segundo, a $0,12 \%$.

\section{Conclusões}

O percentual de 17,48 dos casos revisto na citopatologia ginecológica é elevado e estabelece um dado valioso de comparação com outros programas.

A identificação prévia ao escrutínio dos casos de alto risco e seu encaminhamento obrigatório ao citopatologista mostraram-se uma prática acertada, visto que 33,57\% destes casos exibiram algum tipo de anormalidade.

Os 4,56\% de casos totais diagnosticados como anômalos e o 1,95\% de casos diagnosticados como lesões intra-epiteliais estão dentro do padrão internacional. 0 valor de $0,06 \%$ de lesões invasivas identificadas assemeIha-se aos valores do Paraná $(0,05 \%)$.

O total de ASCUS/AGUS diagnosticados (2,56\%) cumpre as recomendações do sistema Bethesda (6), valor que equivale a menos de uma vez e meia o total de lesões intra-epiteliais diagnosticadas (1,95\%).

Entendemos que os dados aqui apresentados traduzem um estrito controle interno da qualidade desenvolvido em laboratório particular e fornecem informações relevantes para o planejamento de um programa de prevenção e controle do câncer uterocervical. 


\section{Referências}

I. Anderson, G.H. et al. A comprehensive internal quality control system for a large cytology laboratory. Acta Cytol., 3 I (6): 895-9, 1987.

2. Baker, R.W. et al. The characteristics of false negative cervical smears: implications for the UK cervical cancer screening programme. J. Clin. Pathol., 52(5): 358-62, 1999.

3. Berkeley, A.S. et al. Advanced squamous cell carcinoma of the cervix with recent normal Papanicolaou tests. Lancet, 2: 375-6, 1980.

4. Cardin, V. Replies to questions on quality assurance measures in cytopathology. Acta Cytol., 32(6): 9 I 5-9, 1988.

5. Koss, L.G.The Papanicolaou test for cervical cancer detection: a triunph and a tragedy. JAMA, 26 I (5): 737-43, 1989.

6. Kurman, R. \& Solomon, D. The Bethesda System for reporting cervical/vaginal cytologic diagnoses: definitions, criteria, and explanatory notes for terminology and specimen adequacy. Nova York: Springer-Verlag Inc., 1994.

7. Kurman, R.J. et al. Interim guidelines for management of abnormal cervical cytology. JAMA, 27 | (23): | 866-9, 1994.

8. Instituto Nacional de Metrologia (Inmetro). Listas de verificação para avaliação de laboratórios, comissão técnica de análises clínicas e de patologia (CTLE-4), 1998.

9. Lynge, E. \& Poll, P. Incidence of cervical cancer following negative smear: a cohort study from Maribo County, Denmark. Am. J. Epidemiol., I 24(3): 345-52, 1986.

10. Martin, P.L. How preventable is invasive cervical cancer? A community study of preventable factors. Am. J. Obstet. Gynecol., I I 3: 541-8, 1972.
I I. Instituto Nacional de Câncer, Coordenação de Programas de Controle do Câncer, Pro-Onco - Sociedade Brasileira de Citopatologia. Nomenclatura e controle de qualidade nos programas de rastreamento do câncer cérvico-uterino, 1993.

12. Norell, N.D. et al. False-negative cytology rates in patients in whom invasive cervical cancer subsequently developed. Obstet. Gynecol., 60: 41-5, 1982.

13. Paterson, M.E.L. et al. Cervical smear histories of 500 women with invasive cervical cancer in Yorkshire. Br. Med. J., 289: 896-8, 1984.

14. Roshental, D.L. Replies to questions on quality assurance measures in cytopathology. Acta Cytol., 32(6): 929-31, 1988

15. Rylander, E. Negative smears in women developing invasive cervical cancer. Acta Obstet. Gynecol. Scand., 56: I I 5-8, 1977.

16. Travers, $\mathrm{H}$. Quality assurance indicators in anatomic pathology. Arch. Pathol. Lab. Med., I | 4: I| 49-56, 1990.

17. Trent Gynaecological Pathology Quality Assurance Group. Inadequate cervical smears: results of an educational slide exchange scheme. Cytopathology, I O(I): 16-24, 1999.

18. Van der Graaf, Y. et al. Screening errors in cervical cytology screening. Acta Cytol., 31: 434-8, 1987.

19. Walker, E.M. et al. A retrospective review of cervical cytology in women developing invasive squamous cell carcinoma. Br. J. Obstet. Gynaecol., 90: 1087-91, 1983.

20. Zardawi, I.M et al.The role of peer review in internal quality assurance in cytopathology. Pathology, 30(3): 309-13, 1998. 